\title{
Infrared Detection and CT Analysis on High-Performance Concrete after Exposure to High Temperature
}

\author{
Du Hongxiu ${ }^{1, a, *}$, Xu Yaoyao ${ }^{1, b}$ \\ ${ }^{1}$ Department of Architecture and Civil Engineering,Taiyuan University of Technology, Yingze western street, \\ Taiyuan, China

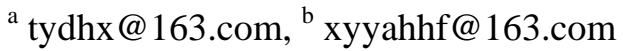 \\ *corresponding author: Du Hongxiu, Prof.
}

Keywords: high-performance concrete, polypropylene fiber, high temperature, infrared thermal image, CT.

\begin{abstract}
The experiments of high-temperature for C60 high-performance concrete (HPC) mixed with $0 \%$ and $0.2 \%$ polypropylene fiber (PP) were carried out, respectively. The infrared thermographic inspection technology was applied to detect the damage of concrete after exposure to $20^{\circ} \mathrm{C} \sim 700^{\circ} \mathrm{C}$, then the relationship among the temperature, the average temperature rise of infrared thermal image and cube compressive strength of concrete was established. The concrete at $20^{\circ} \mathrm{C}$, $300^{\circ} \mathrm{C}, 400^{\circ} \mathrm{C}, 500^{\circ} \mathrm{C}$ were scanned by X-ray computed tomography (CT) and analysed the CT images. The experimental results show that with the increasing of temperature, the average temperature rise of infrared thermal image is increasing, the cube compressive strength of concrete is decreasing and there are more cracks in the CT images. When the temperature is lower than $400^{\circ} \mathrm{C}$, the pores above $10 \mu \mathrm{m}$ of fiber concrete is less than the plain concrete. The polypropylene fibers can improve and restrain the deterioration of concrete in micro-level.
\end{abstract}

\section{Introduction}

The high-performance concrete has been widely applied in practical engineering in recent years. The internal structure of high-strength and high-performance concrete is more compact, higher strength and better durability[1], but the explosive spalling is more prone to occur at high temperature and reduces the strength of concrete significantly[2]. Related studies indicate that the performance of concrete at high temperature can be improved by adding the suitable quantity and size of polypropylene fiber into concrete[3], it's due to the holes that left by the molten fibers at high temperature can be used as the channels for releasing the internal pore pressure of concrete.

The high temperature tests on the C60 HPC mixed with $0 \%$ and $0.2 \%$ polypropylene fiber respectively were carried out in the paper. The cube compressive strength and the infrared thermal images of concrete after $20^{\circ} \mathrm{C} \sim 700^{\circ} \mathrm{C}$ were obtained, the relationship among the temperature, the average temperature rise of infrared thermal image and cube compressive strength was established. C60 high-performance concrete at $20^{\circ} \mathrm{C}, 300^{\circ} \mathrm{C}, 400^{\circ} \mathrm{C}$ and $500^{\circ} \mathrm{C}$ were scanned by X-ray CT, analysed the CT images and defects of concrete. The influence of fiber on the creation and growth of interior cracks in concrete was analysed. Explore the relationship between microscopic damage of concrete and macroscopic properties.

\section{Experiment}

\subsection{Materials and Mix Proportion}

The materials used in this study were: cement, P.O 42.5; river sand with fineness modulus of 2.93 as fine aggregate, well gradation; limestone gravels with a $5 \sim 20 \mathrm{~mm}$ particle size distribution as coarse aggregates; Granulated blast furnace slag powder S95; class II fly ash; polycarboxylate superplasticizer and water reduction ratio is $28 \%$; tap water; polypropylene fiber with $8 \mathrm{~mm}$ in length, $25 \mu \mathrm{m}$ in diameter, melting point about $165^{\circ} \mathrm{C}$. The mixture ratio of test is shown in Table 1 . 
The volume fractions of polypropylene fiber are $0 \%$ and $0.2 \%$.

Table 1 The mixture ratio of C60 high-performance concrete $\left(\mathrm{kg} / \mathrm{m}^{3}\right)$.

\begin{tabular}{|c|c|c|c|c|c|c|}
\hline Cement & Sand & Gravel & Slag & Fly ash & Water & Superplasticizer \\
\hline 412.0 & 711.2 & 1024 & 55.2 & 55.2 & 165.2 & 12.64 \\
\hline
\end{tabular}

\subsection{Specimen Preparation}

The C60 high-performance concrete samples with the cube standard were prepared and maintained according to Technical Specification for Application of High Performance Concrete (CECS207-2006). The curing age of concrete was 28d, thermocouples was embedded in the center of the specimen. The test pieces were divided into two series, one was the plain concrete without fiber (NP) and the other one was mixed with $0.2 \%\left(1.8 \mathrm{~kg} / \mathrm{m}^{3}\right)$ polypropylene fiber $(0.2 \% \mathrm{PP})$. The random core samples were drilled from concrete samples and the size was $\Phi 6 \mathrm{~mm} \times 20 \mathrm{~mm}$ for later CT scan.

\subsection{Test Methods}

\subsubsection{The Simulation of High Temperature Test}

The SRJX box-type resistance furnace was used for heating concrete in this experiment, rated temperature is $1200^{\circ} \mathrm{C}$, power of $15 \mathrm{~kW}$, the heating rate is $13^{\circ} \mathrm{C} / \mathrm{min}$. The target temperatures were $100^{\circ} \mathrm{C}, 200^{\circ} \mathrm{C}, 300^{\circ} \mathrm{C}, 400^{\circ} \mathrm{C}, 500^{\circ} \mathrm{C}, 600^{\circ} \mathrm{C}$ and $700^{\circ} \mathrm{C}$. When the temperature of the embedded thermocouple in the center of the specimen is the same as the temperature of the furnace, the specimen continues to burn for 15 minutes, and then consider that the sample reaches the target temperature. The specimen at room temperature $\left(20^{\circ} \mathrm{C}\right)$ acted as a control group.

\subsubsection{Infrared Detection Method}

The infrared thermographic inspection technology is a new non-destructive testing method, which uses infrared detector and optical imaging objective to receive the infrared radiation energy distribution of the tested concrete. The TH9100WV infrared thermal imager was used to shoot and got infrared thermal images of concrete after different temperatures. The emissivity of concrete set to 0.92 and 4 infrared bulbs with $175 \mathrm{~W}$ were used as the heating stimulator. The distance between concrete and heating stimulator was $1 \mathrm{~m}$. The heating time was $3 \mathrm{~min}$ (took pictures for concrete when it at room temperature and after heating time). Analysed the infrared thermal images and got the values of average temperature rise.

\subsubsection{The Method of CT Scanning}

$\mathrm{X}$-ray computed tomography is a new imaging technique that combines computer and radiology. CT scan instrument is the $\mu$ CF225FCB high precision micro-CT experimental system developed by Taiyuan University of Technology and the Chinese Academy of Engineering Physics Application of Electronic Research Institute, including high precision turntable and fixture, microfocus X-ray machine, digital flat panel detector, horizontal mobile mechanism, frame and the collection and analysis system, etc. Support the use of high-temperature atmosphere furnace and CT. The samples were put into the furnace and heated to the target temperature of: $20^{\circ} \mathrm{C}, 300^{\circ} \mathrm{C}, 400^{\circ} \mathrm{C}$ and $500^{\circ} \mathrm{C}$. The samples could be used for CT scanning when the target temperature has been reached and maintained constant for 15 min.

\section{Results and Discussion}

\subsection{Analysis of infrared thermal image}

The infrared thermal images of plain concrete and polypropylene fiber concrete after different fire temperatures are shown in Figure 1 and Figure 2. According to figures, the temperature rise of infrared thermal image of plain concrete and polypropylene fiber concrete follow the same trend. 
With the increasing temperature, the thermal damage of concrete becomes serious and there are many cracks on the surface. The heat in the cracks forms heat accumulation, which makes the average temperature of infrared thermal image higher.

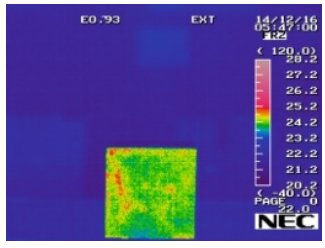

$20^{\circ} \mathrm{C}$

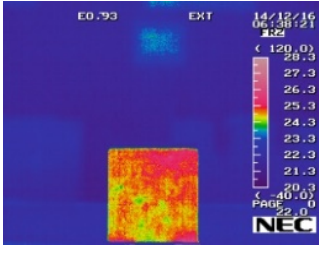

$400^{\circ} \mathrm{C}$

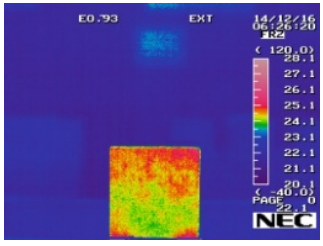

$100^{\circ} \mathrm{C}$

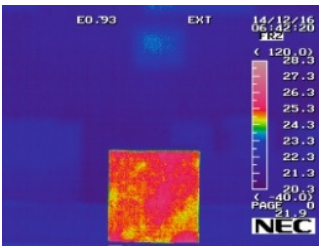

$500^{\circ} \mathrm{C}$

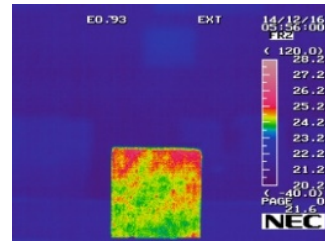

$200^{\circ} \mathrm{C}$

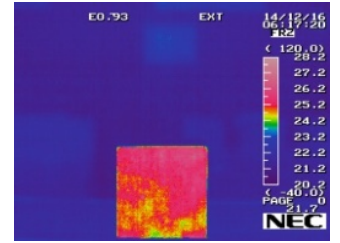

$600^{\circ} \mathrm{C}$

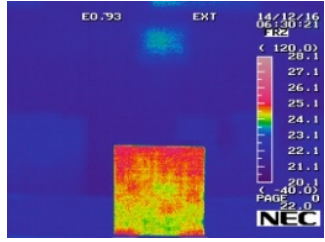

$300^{\circ} \mathrm{C}$

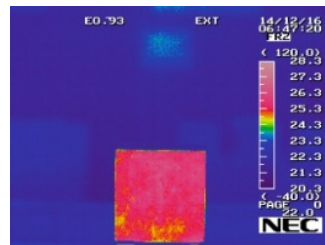

$700^{\circ} \mathrm{C}$

Figure 1 Infrared thermal images of plain concrete after heating for $3 \mathrm{~min}$.

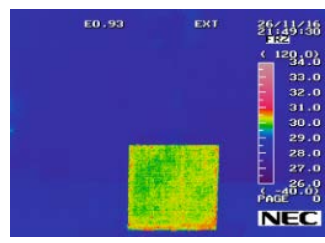

$20^{\circ} \mathrm{C}$

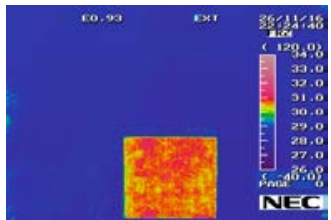

$400^{\circ} \mathrm{C}$

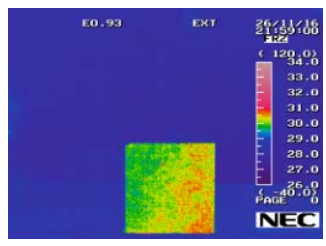

$100^{\circ} \mathrm{C}$

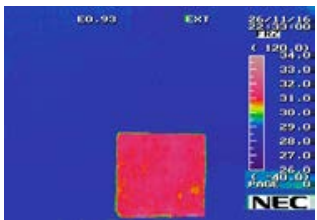

$500^{\circ} \mathrm{C}$

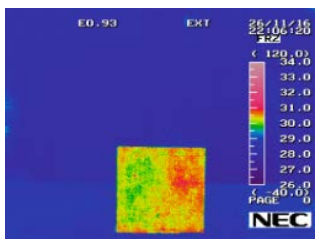

$200^{\circ} \mathrm{C}$

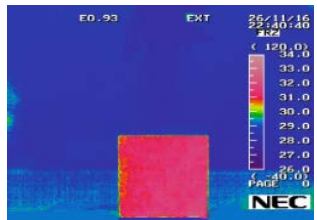

$600^{\circ} \mathrm{C}$

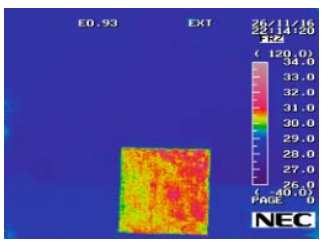

$300^{\circ} \mathrm{C}$

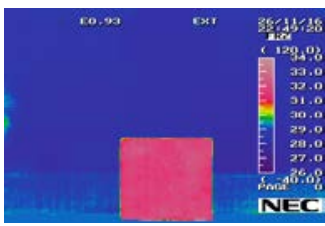

$700^{\circ} \mathrm{C}$

Figure 2 Infrared thermal images of fiber concrete after heating for $3 \mathrm{~min}$.

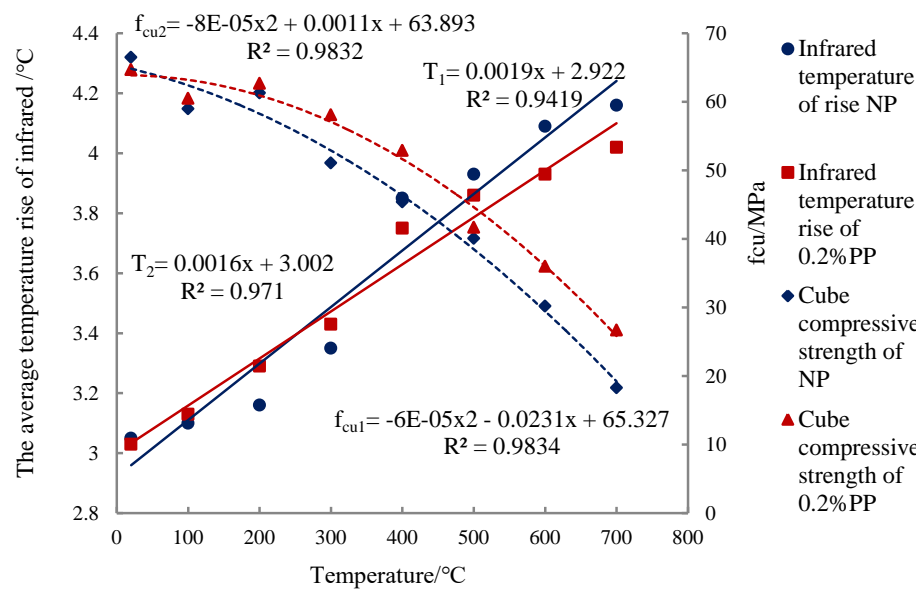

Figure 3 The relationship among the temperature, the average temperature rise of infrared thermal image and cube compressive strength.

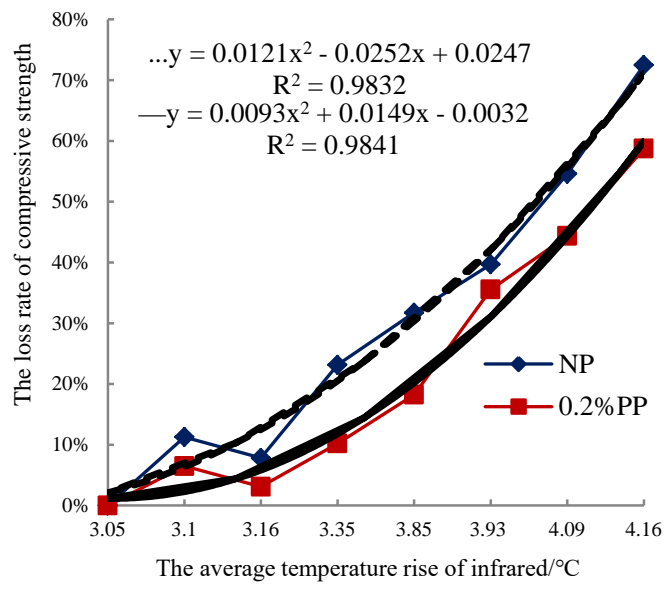

Figure 4 The relationship between the loss rate of cube compressive strength of concrete and the average temperature rise of infrared.

The relationship among the temperature, the average temperature rise of infrared thermal image and cube compressive strength is shown in Figure 3 (" 1 " represents NP, " 2 " represents $0.2 \% \mathrm{PP}$ in 
figures). According to the figure, the average temperature rise of infrared thermal image of fiber concrete is higher than that of plain concrete before $300^{\circ} \mathrm{C}$, but it's opposite after $300^{\circ} \mathrm{C}$. Before $300^{\circ} \mathrm{C}$, the low fiber's thermal conductivity and low density of fiber-concrete interface which make the low thermal conductivity of fiber concrete, thus the infrared temperature is slightly higher. The cube compressive strength of concrete is decreasing with the increasing temperature. The strength increased in a small degree at $100^{\circ} \mathrm{C} \sim 200^{\circ} \mathrm{C}$, the reason is that the free water in the concrete is evaporated and makes the bonding of cement more closely. Dehydration of the gel at low temperatures enhances the bonding strength between gel and aggregate, it offsets the bonding strength loss that caused by the destruction of cement paste-aggregates to some extent[4]. The cube compressive strength of fiber concrete is higher than that of plain concrete.

The relationship between the loss rate of cube compressive strength of concrete and the average temperature rise of infrared is shown in Figure 4. According to figure, the loss rate of cube compressive strength of concrete that includes fiber concrete and plain concrete are increasing with the increasing average temperature of infrared thermal image. Under the same infrared temperature, the loss rate of cube compressive strength of fiber concrete is lower than that of plain concrete.

\subsection{Analysis of C60 High-Performance Concrete with CT Scanning}

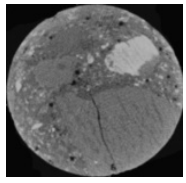

$20^{\circ} \mathrm{C}$
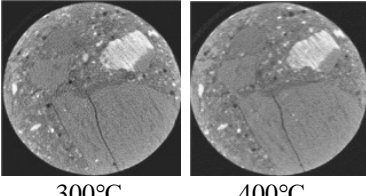

$400^{\circ} \mathrm{C}$

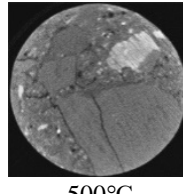

$500^{\circ} \mathrm{C}$

(1) The CT images of the 750th layers of plain concrete.

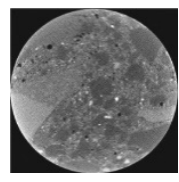

$20^{\circ} \mathrm{C}$

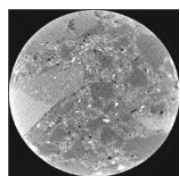

$300^{\circ} \mathrm{C}$

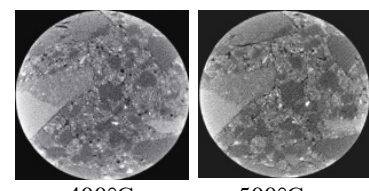

$500^{\circ} \mathrm{C}$

(2) The CT images of the 750th layers of fiber concrete

Figure 5 The CT images of the 750th laye of fiber concrete and plain concrete at different temperatures.

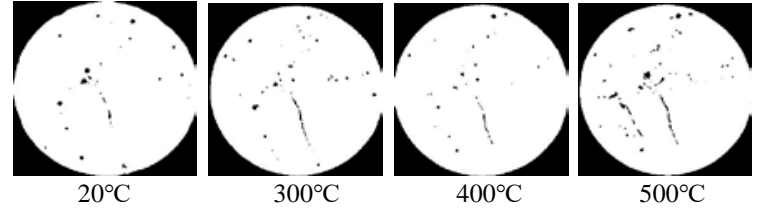

(1) The binary images of the 750th layers of plain concrete

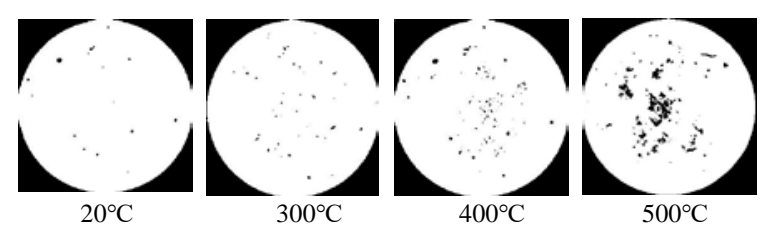

(2) The binary images of the 750th layers of fiber concrete.

Figure 6 The binary images of the 750th layers of fiber concrete and plain concrete at different temperatures.

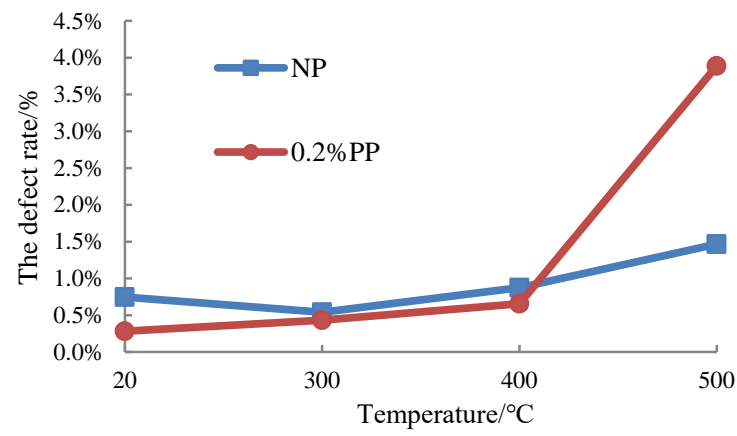

Figure 7 The relationship between different temperatures and defect rates of concrete at the 750th layer.

The CT images of the 750th layers of fiber concrete and plain concrete at different temperatures are shown in Figure 5, the binary images are shown in Figure 6. According to figures, a long main crack and some pores can be seen in the plain concrete at room temperature, there is a longer crack at $300^{\circ} \mathrm{C}$, cracks continue to expand and most of them are distributed around coarse aggregates and pores at $400^{\circ} \mathrm{C}$, the cracks become more obvious and interconnect with each other when the temperature reaches $500^{\circ} \mathrm{C}$. In general, with the increasing of temperature, the cracks continue to expand and interconnect with each other, the short cracks extend into longer cracks. With the 
increasing of temperature, the overall trend of cracks in fiber concrete is same as the plain concrete, the main difference is the mode of cracks propagation. For fiber concrete, there is a little difference between the cracks at $300^{\circ} \mathrm{C}$ and that at room temperature. When the temperature reaches $400^{\circ} \mathrm{C}$, there are many short cracks can be seen from CT images and expand partially, but the long cracks haven't appeared. Cracks and pores expand seriously at $500^{\circ} \mathrm{C}$. The main reason for the difference is the holes that left by the molten fibers at high temperature can be used as the channels for releasing the internal pore pressure of concrete[5]. The holes also make cracks and pores only expand at weak points of mortar so as to the long cracks can't generate.

The relationship between different temperatures and defect rates at the 750th layer is shown in Figure 7. According to figure, the defect rate of plain concrete is higher than that of fiber concrete before $400^{\circ} \mathrm{C}$, it's opposite after $400^{\circ} \mathrm{C}$. The holes that left by the molten fibers at high temperature can be used as the channels for releasing the internal pore pressure of concrete, so as to improve and restrain the deterioration of concrete, thus the pores above $10 \mu \mathrm{m}$ of fiber concrete is less than the plain concrete when the temperature is below $400^{\circ} \mathrm{C}$. The higher the temperature, the higher the defect rate.

\section{Conclusion}

Draw the following conclusions from this paper:

(1) With the increasing of temperature, the average temperature rise of infrared thermal image is increasing and the cube compressive strength of concrete is decreasing. The average temperature risie of infrared thermal image of fiber concrete is higher than that of plain concrete before $300^{\circ} \mathrm{C}$, but it's opposite after $300^{\circ} \mathrm{C}$.

(2) The more serious thermal damage of concrete, the more cracks in the CT images. When the temperature is lower than $400^{\circ} \mathrm{C}$, the pores above $10 \mu \mathrm{m}$ of fiber concrete is less than the plain concrete.

(3) There are long cracks in plain concrete and interconnect with each other. On the contrary, the cracks are shorter and there are no long cracks when the concrete mixed with fibers. The polypropylene fibers can improve and restrain the deterioration of concrete.

\section{Acknowledgements}

This study is supported by the National Natural Science Foundation (Grant No. 51478290). The authors thank the support of Taiyuan University of Technology, and the postgraduates of the building materials laboratory for their assistance.

\section{References}

[1] Zhao Lihong, Peng Gaifei, Qi Guoliang and Liu Yefeng. (2003) An Experimental Study on Residual Mechanical Properties of Fibre-Toughened High Performance Concrete Exposed to High Temperatures. Concrete, 12, 8-11.

[2] Ge Weihua, Du Hongxiu and Yan Ruizhen. (2013) The Influence of Diameter of Polypropylene Fiber on High-Strength Concrete after High Temperature. China Concrete and Cement Products, 9, 48-50.

[3] CLAYTON, N. (2000) Fire Performance of High-Grade Concrete. Institution of Civil Engineers. Research Focus, 7, 1025-1030.

[4] Li Min, Qian Chunxiang and Sun Wei. (2002) Investigation of Influence of PP Fiber on Performances of HPC under High Temperature. Journal of Building Materials, 10, 34-36.

[5] Ju Liyan and Zhang Xiong. (2004) The Varying Rule and The Non-Destructive Measuring of High Performance Concrete after Fire. Industrial Construction, 1, 25-28. 